\title{
Complications following central corpectomy in 468 consecutive patients with degenerative cervical spine disease
}

\author{
Sauradeep Sarkar, MBBS, Bijesh R. Nair, MCh, and Vedantam Rajshekhar, MCh \\ Department of Neurological Sciences, Christian Medical College, Vellore, India
}

\begin{abstract}
OBJECTIVE This study was performed to describe the incidence and predictors of perioperative complications following central corpectomy (CC) in 468 consecutive patients with cervical spondylotic myelopathy (CSM) or ossification of the posterior longitudinal ligament (OPLL).

METHODS The authors performed a retrospective review of a cohort of patients who had undergone surgery for CSM $(n=338)$ or OPLL $(n=130)$ performed by a single surgeon over a 15-year period. All patients underwent uninstrumented CC with autologous iliac crest or fibular strut grafting. Preoperative clinical and imaging details were collected, and the type and incidence of complications were studied. Univariate and multivariate analyses were performed to establish risk factors for the development of perioperative complications.
\end{abstract}

RESULTS Overall, $12.4 \%$ of patients suffered at least 1 complication following CC. The incidence of major complications was as follows: $\mathrm{C}-5$ radiculopathy, $1.3 \%$; recurrent laryngeal nerve injury, $0.4 \%$; dysphagia, $0.8 \%$; surgical-site infection, $3.4 \%$; and dural tear, $4.3 \%$. There was 1 postoperative death (0.2\%). On multivariate analysis, patients in whom the corpectomy involved the C-4 vertebral body (alone or as part of multilevel $C C$ ) were significantly more likely to suffer complications $(p=0.004)$. OPLL and skip corpectomy were risk factors for dural tear $(p=0.015$ and $p=0.001$, respectively). No factors were found to be significantly associated with postoperative C-5 palsy, dysphagia, or acute graft extrusion on univariate or multivariate analysis. Patients who underwent multilevel $C C$ were predisposed to surgical-site infections, with a slight trend toward statistical significance $(p=0.094)$. The occurrence of a complication after surgery significantly increased the mean duration of postoperative hospital stay from $5.0 \pm 2.3$ days to $8.9 \pm 6$ days $(p<0.001)$.

CONCLUSIONS Complications following CC for CSM or OPLL are infrequent, but they significantly prolong hospital stay. The most frequent complication following CC is dural tear, for which a diagnosis of OPLL and a skip corpectomy are significant risk factors.

http://thejns.org/doi/abs/10.3171/2016.3.FOCUS1638

KEY WORDS corpectomy; complications; dural tear; infections; C-5 palsy; dysphagia

$\mathrm{C}$ ENTRAL corpectomy (CC), with or without instrumentation, provides excellent outcomes in patients with degenerative cervical myelopathy. $9,13,18,21,36,38,58$ However, $\mathrm{CC}$ can be a technically demanding procedure, and it may be complicated by dysphagia, recurrent laryngeal nerve injury, dural tear, nerve root palsy, wound infection, and graft displacement. Adverse events following cervical spine surgery contribute significantly to patient morbidity by leaving residual neurological deficits, prolong hospital stay, and markedly increase health care expenses. p $^{3,7,24,37,40,41,43,48,62}$
Estimates of complication rates following CC for cervical spondylotic myelopathy (CSM) or ossification of the posterior longitudinal ligament (OPLL) have been limited by small cohort sizes or multiple surgeon involvement. Recent evidence has suggested that advanced age, a diagnosis of OPLL, long-level decompression and combined anterior-posterior approaches are associated with an increased risk of major complications following surgery for CSM or OPLL. ${ }^{67}$ Most contemporary authors have studied complication rates following instrumented ventral decompression of the cervical spine. However, these conclusions cannot

ABBREVIATIONS CC = central corpectomy; CSM = cervical spondylotic myelopathy; LOS = length of stay; OPLL = ossification of the posterior longitudinal ligament; OR = odds ratio. 
be extrapolated to uninstrumented fusion for degenerative cervical spine disease, which does not suffer from hardware-related complications. To the best of our knowledge, no study has specifically examined preoperative variables that might help anticipate surgical morbidity following CC without instrumentation. Given this gap in the current literature, we sought to describe complications following CC without instrumented fusion and identify patient factors that predicted these complications.

\section{Methods}

All patients with CSM or OPLL were considered for $\mathrm{CC}$ unless the compression involved more than 3 vertebral bodies or extended behind the C-2 body. Between September 1991 and October 2007, 482 adult patients underwent $\mathrm{CC}$ at our institution, Christian Medical Center in Vellore, India. In all cases, the procedures were performed by the senior author (V.R.). Fourteen cases involving patients with primary nondegenerative pathology, such as cervical spine trauma, tuberculosis, tumor, or vertebral body dysplasia, were excluded from further analysis. All patients underwent a detailed clinical and radiological evaluation prior to surgery, and perioperative and postoperative patient details were maintained in a prospective database. The patients' functional status at baseline was recorded using the Nurick grading system.

Neutral and dynamic plain cervical spine radiographs were routinely obtained in all patients. MRI was performed preoperatively in 454 patients. In 14 patients who were operated on prior to 1995 , either CT myelography or plain myelography was used. OPLL was diagnosed on the basis of MRI features and radiographs and confirmed intraoperatively. CT of the cervical spine was not performed routinely. Cervical spine curvature was classified by using a line drawn on a lateral radiograph, extending from the most posterior point on the inferior endplate of the C-2 vertebral body to a similar point on C-7. The spine was described as lordotic if all the vertebral bodies were anterior to this line and straight if the intervening vertebral bodies touched the line without crossing it. If the posterior cortical margins of the vertebral bodies extended beyond the line, the spine was classified as kyphotic.

\section{Surgical Technique}

Prophylactic antibiotics were administered for 24 hours after surgery. The protocol consisted of intravenous injection of $1 \mathrm{~g}$ of chloramphenicol at induction followed by 4 additional doses administered at 6-hour intervals. The surgical technique has been documented in previous publications. ${ }^{32,49,50}$ All patients underwent uninstrumented CC using autologous iliac (for 1- or 2-level procedures) or fibular (for 3-level procedures) strut grafts. The procedure is described here in brief. Neck extension was maintained intraoperatively with a rolled sheet placed under the shoulders. Traction was provided with Gardner-Wells tongs. The corpectomy width varied between 14 and 16 $\mathrm{mm}$. After drilling the posterior cortical surface with the aid of an operating microscope, excision of the posterior longitudinal ligament was attempted in the majority of patients. In patients with a densely adherent OPLL or with dural ossification, the ligament was thinned down and then detached ("floating-off technique"). The graft was inserted snugly between mortices drilled in the superior and inferior vertebral levels. On occasion, in the presence of additional ventral compression at a noncontiguous lev$\mathrm{el}$, an isolated discectomy was also performed during the same procedure.

Operating times were noted from the surgeon's notes and were available for $90 \%$ of patients; the operating time ranged from 2 hours to 6 hours, with an average of approximately 3.5 hours. The duration of surgery diminished with increased surgeon experience in the later part of the series. A radiograph was obtained immediately after surgery to confirm correct placement of the graft. Prior to mobilization, all patients were prescribed a Philadelphia collar for continuous use for the first 3-6 months after surgery. Patients undergoing fibular grafting were mobilized at varying intervals after surgery ranging from immediately after surgery to 2 weeks after surgery.

\section{Perioperative Complications}

Complications of interest included dural tear with CSF leak, surgical-site infections, dysphagia and vocal hoarseness, graft displacement, and neurological deterioration. Complications were recorded during the period of hospital stay, and readmissions within 30 days of surgery were also noted. Unexpected medical complications were recorded as and when they occurred. C-5 palsy was defined as unilateral or bilateral upper-extremity weakness or dermatomal sensory loss or radicular pain in the absence of myelopathic signs. Infections were considered superficial if they did not extend deep to the muscular fascia and deep if they involved compartments below the fascia. Superficial infections were treated with antibiotics, while surgical debridement was reserved for deep infections. Postoperative length of stay (LOS) was documented from inpatient records.

\section{Prognostic Variables}

We attempted to identify clinical, radiological, and surgical risk factors for developing complications following CC. Each major complication was also separately evaluated for possible risk factors. Prognostic variables were categorized appropriately and included age at diagnosis $(\geq 50$ years vs $<50$ years), sex, preoperative Nurick grade (poor [Grade 4 or 5] vs high [Grade 1,2, or 3]), diabetes (present vs absent), symptom duration ( $\geq 1$ year vs $<1$ year), primary diagnosis (OPLL versus CSM), preoperative cervical alignment (kyphotic versus nonkyphotic), number of CC levels (2- or 3-level vs 1-level CC and 3-level versus 1- or 2-level CC), type of CC (skip vs contiguous). Because the operating time was less than 4 hours in the vast majority of our patients, and surgery lasting more than 4 hours has been found to be a risk factor for complications in most reported series, operating time was not considered in this analysis.., 52

\section{Statistical Analysis}

Analysis was performed in consultation with a statistician. Data were entered into an electronic database and 
analyzed with SPSS software (version 20.0, IBM Corp.). Descriptive statistics (mean and standard deviation for continuous variables and frequency and percentages for categorical variables) were calculated. Continuous and categorical variables were compared with the Student ttest and chi-square test, respectively. A univariate analysis was used to estimate the odds ratio (OR) and 95\% confidence interval of each variable with respect to development of a particular complication. A stepwise logistic regression model was created using factors selected appropriately from the univariate analysis. Given the overall low incidence of complications, overfitting of the model was avoided by limiting the number of covariates; thus approximately 1 variable was included for every 10 events. Statistical significance was defined by a $\mathrm{p}$ value $<0.05$.

\section{Results}

Clinical and operative details of the cohort are summarized in Table 1. The primary diagnosis was CSM in 330 patients $(70.5 \%)$ and OPLL in 138 patients $(29.5 \%)$. The cohort had an overwhelming male predominance, and 231 patients $(49.4 \%)$ were 50 years of age or older at presentation. In 179 cases (38.2\%), the patients' functional status was considered "poor" (Nurick Grade 4 or 5) prior to surgery. Sixteen patients had undergone prior attempts at cervical spine decompression (anterior approaches in 12 cases, posterior approaches in 4 cases). Preoperative neutral cervical spine radiographs were available for review in 398 cases and demonstrated a lordotic alignment in the majority. Most patients underwent a 2-level corpectomy, and segment most often operated on was C-5. Twenty-four patients underwent a 3-level procedure; including 2 patients who had undergone complete C-4, C-5, and C-6 corpectomies with partial removal of the $\mathrm{C}-3$ and $\mathrm{C}-7$ vertebral bodies as well. No patients underwent a true 4-level CC. Eighteen patients underwent "skip" corpectomies, with corpectomies being performed at C-4 and C- 6 while the intervening C-5 vertebral body was preserved. Data on comorbid illnesses were available for review in 383 patients, approximately $6 \%$ of whom had been diagnosed with diabetes mellitus prior to surgery. Follow-up data were available in 381 patients; the mean follow-up period was $52.1 \pm 40.2$ months. Fusion rates were approximately $88 \%$, studied at 1 year after surgery. However, this study was restricted in scope to the analysis of perioperative complications following CC.

\section{Complications}

Table 2 lists complications following CC, further stratified by the type of pathology. The most frequent complications were dural injury with cerebrospinal fluid (CSF) leak, surgical-site infections, graft extrusion, and C-5 palsy. Fifty-eight patients (12.4\%) suffered at least 1 complication after surgery; 7 of these patients suffering more than 1 complication, but no patient suffering more than 3 complications.

Postoperative C-5 radiculopathy occurred in 6 patients overall. In 4 of these patients, the corpectomy had involved resection of the $\mathrm{C}-5$ vertebral body. The remaining 2 patients had undergone a single-level C-6 CC and a C-4/C-6 skip CC, respectively.
TABLE 1. Baseline characteristics of the cohort $(n=468)$

\begin{tabular}{lc}
\hline \multicolumn{1}{c}{ Characteristic } & Value \\
\hline Mean age at diagnosis (yrs) & $48.6 \pm 9.7$ \\
\hline Sex & $440(94.0 \%)$ \\
Male & $28(6.0 \%)$ \\
Female & $21(5.5 \%)$ \\
\hline Diabetes mellitus $†$ & $21.3 \pm 30.7$ \\
\hline Mean duration of symptom (mos) & $3.2 \pm 1.0$ \\
\hline Mean preop Nurick grade & \\
\hline Pathology & $330(70.5 \%)$ \\
CSM & $138(29.5 \%)$ \\
OPLL & \\
\hline Preop sagittal alignment† & $275(69.1 \%)$ \\
Lordotic & $93(23.4 \%)$ \\
Straight & $30(7.5 \%)$ \\
Kyphotic & $155(33.1 \%)$ \\
Number of operated segments & $289(61.8 \%)$ \\
1 & $24 \ddagger(5.1 \%)$ \\
2 & $18(3.8 \%)$ \\
3 & \\
Skip corpectomies & 4 \\
Levels included in corpectomy & 168 \\
C-3 & 357 \\
C-4 & 271 \\
C-5 & 7 \\
C-6 & \\
C-7 & \\
\hline
\end{tabular}

\footnotetext{
* Values represent numbers of patients or cases (\%) unless otherwise indicated. Mean values are presented with standard deviations.

$\dagger$ Data on diabetes mellitus were available for only 383 patients and the percentage was calculated accordingly.

$\ddagger$ Includes 2 patients who underwent partial corpectomies at the superior and inferior adjacent vertebral levels.
}

Dural tears, more common in patients with OPLL, were managed intraoperatively with a fascial onlay graft with an additional layer of gelatin sponge. Five patients (27.8\%) undergoing skip CC developed dural tears; 3 of these 5 patients had OPLL. In all cases, a lumbar subarachnoid drain was inserted postoperatively, followed by restricted ambulation for 5-7 days. ${ }^{27}$ No patient with dural tears developed meningitis, pseudomeningocele, or CSF fistula, and none required reoperation for dural repair. Recurrent laryngeal nerve injuries occurred in 2 patients who developed vocal hoarseness postoperatively.

Infections occurred in $3.4 \%$ of cases overall, and in more than half of these cases the infection occurred at the iliac crest graft site, although there was no statistically significant difference by site (neck incision vs graft site, $p$ $=0.802$ ). A bacterial isolate could be obtained from swab cultures in only 4 cases: coagulase-negative Staphylococcus in 2 cases, methicillin-sensitive $S$. aureus in 1 case, and Escherichia coli in 1 case. There were no deep infections; all infections responded well to antibiotic therapy without the need for surgical debridement.

One patient developed a hematoma at the iliac bone graft site that was drained via a bedside procedure. Graft displacement was seen in 8 cases overall and was associ- 
TABLE 2. Complications following central corpectomy for CSM or OPLL*

\begin{tabular}{|c|c|c|c|}
\hline Variable & $\begin{array}{c}\text { Total } \\
(n=468)\end{array}$ & $\begin{array}{c}\text { CSM } \\
(n=330)\end{array}$ & $\begin{array}{c}\text { OPLL } \\
(n=138)\end{array}$ \\
\hline Patients w/ any complication & $58(12.4 \%)$ & $39(11.8 \%)$ & $19(13.8 \%)$ \\
\hline $\begin{array}{l}\text { Patients w/ } \\
\text { No complications } \\
1 \text { complication } \\
2 \text { complications }\end{array}$ & $\begin{aligned} 410 & (87.6 \%) \\
51 & (10.9 \%) \\
7 & (1.5 \%)\end{aligned}$ & $\begin{array}{c}291(88.2 \%) \\
35(10.6 \%) \\
4(1.2 \%)\end{array}$ & $\begin{array}{c}119(86.2 \%) \\
16(11.6 \%) \\
3(0.2 \%)\end{array}$ \\
\hline \multicolumn{4}{|l|}{ Approach related } \\
\hline C-5 palsy & $6(1.3 \%)$ & $4(1.2 \%)$ & $2(1.4 \%)$ \\
\hline $\begin{array}{l}\text { Recurrent laryngeal } \\
\text { nerve injury }\end{array}$ & $2(0.4 \%)$ & $2(0.6 \%)$ & 0 \\
\hline Dysphagia & $4(0.9 \%)$ & $4(1.2 \%)$ & 0 \\
\hline Dural tear w/ CSF leak & $20(4.3 \%)$ & $8(2.4 \%)$ & $12(8.7 \%)$ \\
\hline Operated site hematoma & $1(0.2 \%)$ & $1(0.3 \%)$ & 0 \\
\hline \multicolumn{4}{|l|}{ Graft related } \\
\hline Graft extrusion & $8(1.7 \%)$ & $6(1.8 \%)$ & $2(1.4 \%)$ \\
\hline Donor site hematoma & $1(0.2 \%)$ & $1(0.3 \%)$ & 0 \\
\hline Donor site hernia & $1(0.2 \%)$ & $1(0.3 \%)$ & 0 \\
\hline \multicolumn{4}{|l|}{ Surgical-site infections } \\
\hline Total & $16(3.4 \%)$ & $12(3.6 \%)$ & $4(2.9 \%)$ \\
\hline Neck & $7(1.5 \%)$ & $4(1.2 \%)$ & $3(2.2 \%)$ \\
\hline Graft site & $9(1.9 \%)$ & $8(2.4 \%)$ & $1(0.7 \%)$ \\
\hline \multicolumn{4}{|l|}{ Medical/anesthesia-related } \\
\hline Respiratory failure/arrest & $2(0.4 \%)$ & 0 & $2(1.4 \%)$ \\
\hline Pneumonia & $2(0.4 \%)$ & 0 & $1(0.7 \%)$ \\
\hline Heart failure & $1(0.2 \%)$ & $1(0.3 \%)$ & 0 \\
\hline $\begin{array}{l}\text { Duodenal perforation w/ } \\
\text { peritonitis \& death }\end{array}$ & $1(0.2 \%)$ & $1(0.3 \%)$ & 0 \\
\hline
\end{tabular}

* Values are numbers of patients or complications (\%).

ated with fracture of the graft in 2 patients. This complication was more frequent in the earlier part of the series. Five of these patients reported symptoms referable to graft migration: neck or shoulder pain in 3 cases, dysphagia in 1 case, and neurological deterioration in 1 case. In the other 3 patients, slippage was detected on routine postoperative radiographs performed to confirm graft position. Five of the 8 patients with graft displacement patients required a second operative procedure to reposition the graft. The 2 patients with fractured grafts were placed on bed rest for 6 weeks. The patient who had suffered neurological deterioration as a result of graft migration made a gradual recovery, improving from Nurick Grade 3 at baseline to Grade 2 at 6.5 years follow-up.

A 63-year-old patient developed acute neurological deterioration in the immediate postoperative period after a C5-6 corpectomy due to a local hematoma. He underwent an emergency surgical evacuation and made a gradual recovery after surgery. At his last follow-up visit, 10 months after surgery, he reported $25 \%$ improvement as compared with baseline.

Thus, overall, only 2 patients $(0.4 \%)$ developed cordrelated neurological deterioration.
The operative mortality rate was $0.2 \%$ (1 death in the 468 cases included in the analysis). The patient who died was a 71-year-old man, who had a preoperative Nurick grade of 4 . He developed a duodenal perforation with peritonitis after a C-6 corpectomy and underwent emergency surgery but eventually died following complications related to the laparotomy.

\section{Predictors of Complications}

Patients undergoing a skip corpectomy $(\mathrm{p}=0.001)$ or in whom the corpectomy involved the $\mathrm{C}-4$ vertebral body (alone or as part of multilevel CC, $p=0.004$ ) were significantly more likely to suffer any complications following $\mathrm{CC}$ on univariate analysis, as summarized in Table 3. On multivariate analysis, both these factors retained significance.

Factors significantly associated with dural tear on univariate analysis included age $\geq 50$ years $(p=0.026)$, skip corpectomy $(\mathrm{p}<0.001)$, OPLL $(\mathrm{p}=0.004)$, and diabetes mellitus $(\mathrm{p}=0.029)$, as shown in Table 4. On multivariate analysis using 3 covariates, OPLL $(\mathrm{p}=0.015)$ and skip corpectomy $(\mathrm{p}=0.001)$ remained significant risk factors for dural tear. No factors were found to be significantly associated with postoperative C-5 palsy, dysphagia, or acute graft extrusion on univariate or multivariate analysis. Patients with multilevel and skip CC were predisposed to surgical-site infections, with a slight trend toward significance ( $p=0.094$ and $p=0.088$, respectively), as shown in Table 5. However, no factors were independently predictive of infection on logistic regression analysis.

\section{Complications and LOS After Surgery}

Data regarding LOS after CC could be retrieved in 379 patients. Overall, the mean LOS was $5.44 \pm 3.33$ days (range 2-25 days). In general, LOS was longer in patients with diabetes mellitus $(\mathrm{p}=0.042)$, patients with OPLL ( $\mathrm{p}$ $=0.027)$, and those who underwent multilevel $(p=0.014)$ or skip corpectomy $(p<0.001)$. The occurrence of any complication, quite predictably, was associated with a significant increase in the mean LOS (from $5.0 \pm 2.3$ days to $8.9 \pm 6$ days, $p<0.001$ ). Patients who developed medical complications after surgery tended to have longer LOS than patients who suffered surgery-related complications $(p=0.072)$. LOS did not differ significantly when stratified by type of surgical complication $(p=0.902)$. Two patients required readmission for surgical infections that developed after discharge, and 1 patient was transferred to a cardiology service for further treatment of cardiac failure.

\section{Discussion}

Increased soft tissue exposure, bone resection, and operating times in $\mathrm{CC}$ have been variably associated with increased instrumentation and graft-related morbidity, in comparison with other ventral approaches, notably anterior cervical discectomy and fusion. ${ }^{33-35,65}$ However, in the hands of an experienced surgeon, $\mathrm{CC}$ can be performed safely and provides excellent ventral decompression in patients with both CSM and/or OPLL. To the best of our knowledge, this study presents complications rates in the largest cohort of patients undergoing $\mathrm{CC}$ published in the 
TABLE 3. Univariate and multivariate analyses of risk factors associated with any complication $(n=58)$ following CC

\begin{tabular}{|c|c|c|c|c|}
\hline \multirow[b]{2}{*}{ Risk Factor } & \multicolumn{2}{|c|}{ Univariate Analysis } & \multicolumn{2}{|c|}{ Multivariate Analysis } \\
\hline & OR $(95 \% \mathrm{Cl})$ & $p$ Value & OR $(95 \% \mathrm{Cl})$ & $p$ Value \\
\hline Age $\geq 50$ yrs & $1.532(0.877-2.674)$ & $0.134^{*}$ & $1.152(0.620-2.138)$ & 0.655 \\
\hline Symptom duration $\geq 1 \mathrm{yr}$ & $1.323(0.763-2.295)$ & 0.319 & & \\
\hline Preop Nurick grade of 4 or 5 & $0.977(0.554-1.722)$ & 0.936 & & \\
\hline 3-level corpectomy & $0.630(0.144-2.752)$ & 0.539 & & \\
\hline OPLL & $1.191(0.661-2.146)$ & 0.560 & & \\
\hline Skip corpectomy & $5.208(1.929-14.057)$ & $0.001^{*}$ & $3.237(1.076-9.736)$ & 0.037 \\
\hline C-4 included in corpectomy & $2.291(1.304-34.025)$ & $0.004^{*}$ & $1.815(0.947-3.478)$ & 0.072 \\
\hline C-5 included in corpectomy & $0.974(0.512-1.853)$ & 0.936 & & \\
\hline C-6 included in corpectomy & $0.813(0.468-1.413)$ & 0.463 & & \\
\hline Diabetes mellitus & $2.259(0.788-6.470)$ & $0.129^{*}$ & $2.102(0.695-6.359)$ & 0.188 \\
\hline Previous cervical surgery & $1.666(0.460-6.031)$ & 0.437 & & \\
\hline Preop kyphosis & $0.251(0.033-1.895)$ & 0.180 & & \\
\hline
\end{tabular}

* Factor inserted into the logistic regression model.

literature. Data from our cohort of 468 cases indicate that, overall, complications associated with this procedure were infrequent and comparable to those reported in the contemporary literature on $\mathrm{CC}$ with or without instrumented fusion. Furthermore, our cohort is notable for the absence of any hardware-related complications due to the lack of instrumented fusion.

Boakye et al..$^{5}$ conducted a study on complications in 1560 patients treated at Veteran Affairs clinics over a 10 -year period, demonstrating that age greater than 80 years, Type 1 diabetes mellitus, American Society of Anesthesiologists class greater than 3, and dependent functional status as predictors of complications following CC. Based on combined evidence from 60 citations, a recent review concluded that old age, longer operating time, and a 2-stage circumferential decompression were associated with increased perioperative complications. ${ }^{67}$ Interestingly, among the numerous variables analyzed in our study, the execution of a skip corpectomy was found to be significantly associated with the risk of developing any complication after CC. Skip corpectomies are usually performed in the setting of extensive ventral compression, and the preservation of the C-5 vertebral body is believed to con- fer greater stability and strength to the construct. ${ }^{4,10}$ The extensive exposure and the use of 2 graft constructs might be considered factors contributing to the higher complication rates in this group of patients. If these were the only factors, then patients undergoing 3-level CC should also be at higher risk for complications. Since 3-level CC was not seen as risk factor for higher rate of complications, the real reasons why patients undergoing skip corpectomies had a higher rate of complications remain unclear.

We report a relatively low rate of dysphagia compared with other studies reporting complication rates with CC. ${ }^{17,65}$ This may be a consequence of the shorter average duration of surgery ( $<4$ hours). More importantly, our definition of dysphagia led us to include only those patients who needed a nasogastric tube or parenteral feeding due to the dysphagia and not patients who only complained of pain during swallowing. Similarly, recurrent laryngeal nerve injury was only considered in dysphonic patients with laryngoscopic evidence of vocal cord palsy.

\section{Dural Tear}

CSF leaks due to dural tears contribute significantly to patient morbidity following $\mathrm{CC}$, and could be associ-

TABLE 4. Univariate and multivariate analyses of risk factors associated with dural tear $(n=20)$ following CC

\begin{tabular}{|c|c|c|c|c|}
\hline \multirow[b]{2}{*}{ Risk Factor } & \multicolumn{2}{|c|}{ Univariate Analysis } & \multicolumn{2}{|c|}{ Multivariate Analysis } \\
\hline & OR $(95 \% \mathrm{Cl})$ & p Value & OR $(95 \% \mathrm{Cl})$ & $\mathrm{p}$ Value \\
\hline Age $\geq 50$ yrs & $3.222(1.152-9.016)$ & $0.026^{*}$ & $2.541(0.879-7.346)$ & 0.085 \\
\hline Symptom duration $\geq 1 \mathrm{yr}$ & $1.482(0.602-3.648)$ & 0.392 & & \\
\hline Preop Nurick grade of 4 or 5 & $0.858(0.336-2.192)$ & 0.749 & & \\
\hline 3-level corpectomy & $0.973(0.125-7.586)$ & 0.979 & & \\
\hline Skip corpectomy & $11.154(3.522-35.321)$ & $<0.001^{*}$ & 7.647 (2.284-25.599) & 0.001 \\
\hline OPLL & $3.833(1.531-9.600)$ & $0.004^{*}$ & $3.258(1.263-8.402)$ & 0.015 \\
\hline Diabetes mellitus & $4.474(1.169-17.118)$ & 0.029 & & \\
\hline Previous cervical surgery & $3.444(0.728-16.306)$ & 0.119 & & \\
\hline
\end{tabular}

\footnotetext{
* Factor inserted into the logistic regression model.
} 
TABLE 5. Univariate and multivariate analyses of risk factors associated with surgical-site infections $(n=16)$ following CC

\begin{tabular}{|c|c|c|c|c|}
\hline \multirow[b]{2}{*}{ Risk Factor } & \multicolumn{2}{|c|}{ Univariate Analysis } & \multicolumn{2}{|c|}{ Multivariate Analysis } \\
\hline & OR $(95 \% \mathrm{Cl})$ & $p$ Value & OR $(95 \% \mathrm{Cl})$ & $\mathrm{p}$ Value \\
\hline Age $\geq 50$ yrs & $1.027(0.379-2.784)$ & 0.958 & & \\
\hline Symptom duration $\geq 1 \mathrm{yr}$ & $0.707(0.253-1.979)$ & 0.509 & & \\
\hline Preop Nurick grade of 4 or 5 & $2.118(0.774-5.791)$ & 0.144 & & \\
\hline Multilevel corpectomy & $3.582(0.804-15.963)^{*}$ & 0.094 & $3.244(0.717-14.681)$ & 0.127 \\
\hline OPLL & $1.090(0.372-3.199)$ & 0.875 & & \\
\hline Skip corpectomy & $3.893(0.815-18.587)^{*}$ & 0.088 & $2.948(0.608-14.303)$ & 0.180 \\
\hline Diabetes mellitus & $1.342(0.167-10.780)$ & 0.782 & & \\
\hline
\end{tabular}

* Factor inserted into the logistic regression model.

ated with pseudomeningocele and fistula formation, airway compromise, and meningitis. ${ }^{12,31,39}$ Unintended dural tears following $\mathrm{CC}$ reported in literature range from $0 \%$ to $8 \% .^{11,14,15,36,38}$ However, the incidence of CSF leak following ventral decompression of cervical OPLL is significantly higher as compared with CSM, since the disease process in OPLL intimately involves the dura. ${ }^{1,8,23,63,64}$

Our results indicate that OPLL and skip CC are important risk factors for dural tear following CC. Our experience in managing CSF leak following CC for OPLL was the subject of a previous publication, ${ }^{27}$ which also demonstrated that intraoperative repair followed by postoperative lumbar subarachnoid drainage could obviate the need for revision surgery in most patients. Dural tears following CC for CSM were also managed successfully with the same strategy. It is unclear why dural tears were common in patients undergoing skip CC, although we note that the indication for skip CC was OPLL in 50\% of cases. However, it is likely that the high incidence of dural tear with skip CC is also the reason it contributed to increased overall morbidity in our study. A caveat to this remains the fact that the low incidence of dural tear may have contributed to overfitting of the model. Older age was associated with dural tears on univariate analysis in our study. O'Neill et al. ${ }^{46}$ note a similar association and attributed it to age-related loss of tensile strength of the dura, which has also been observed in lumbar spine surgery. ${ }^{20,61,66}$

\section{C-5 Radiculopathy}

Postoperative C- 5 radiculopathy complicates between $1.6 \%$ and $12 \%$ of ventral decompressive procedures for CSM or OPLL. $4,19,25,26,44,47,60,70,71$ The pathogenesis of C-5 radiculopathy is poorly understood and is believed to be multifactorial. Postulated hypotheses include 1) direct intraoperative neural injury, 2) "tethering" of the short C-5 nerve root, and 3) ischemic and reperfusion injury of the spinal cord. ${ }^{53,56,58,68,71}$ In our data, the performance of a C-4 or a C-5 corpectomy was not associated with a greater risk for C-5 palsy ( $\mathrm{p}=0.139$ and $\mathrm{p}=0.588$, respectively), making intraoperative injury to the root unlikely. One of the risk factors suggested by Saunders ${ }^{57}$ is a wide decompression in excess of $15 \mathrm{~mm}$. Odate et al. ${ }^{47}$ also recommended limiting the corpectomy width to less than $15 \mathrm{~mm}$ to avoid C-5 palsy. Traction generated by anterior dural expansion following $\mathrm{CC}$ in the presence of restricted spinal cord movement may possibly cause C-5 root dysfunction, particularly in cases in which the ventral rootlets are adherent to the dura. ${ }^{47,57}$ This may have contributed to the development of this complication in a patient who underwent a C-6 CC in this series. Since all our decompressions were conservative and none exceeded $16 \mathrm{~mm}$, it is likely that this played a role in reducing the number of C-5 palsies noted in our series.

In a subgroup analysis of 255 patients undergoing anterior corpectomy for degenerative disease, Nassr et al. ${ }^{44}$ noted C-5 palsy to be more common in male patients and in those undergoing multilevel procedures. Age and number of corpectomy levels were also the strongest risk factors for postoperative C-5 palsy in the series described by Bydon et al. ${ }^{6}$ A diagnosis of OPLL, ${ }^{25,29}$ particularly in those patients with a high occupying ratio, ${ }^{30}$ also appears to confer an increased risk for C-5 palsy. In our study, no clinical, imaging, or surgical factor was found to be predictive of C-5 palsy. This is likely because of the low incidence of this complication in our series, which makes statistical comparisons less reliable. The role of a prophylactic $\mathrm{C} 4-5$ foraminotomy is controversial; while there may be some merit to it in cases of posterior fusion procedures ${ }^{42,54}$ it remains technically difficult in conjunction with a CC and may be in itself associated with a slight increase in C-5 radiculopathy with anterior approaches. ${ }^{6}$

\section{Graft Migration and Donor Site Morbidity}

Although reconstruction of the vertebral defect following CC was originally performed with an iliac or fibular strut graft, anterior cervical plating is commonly performed today, with most authors also recommending additional instrumentation to stabilize the osseous construct. We have previously published our experience with acute graft extrusion using a "modified keystone" method and shown that the acute graft extrusion rates was less than $2 \%$ and was not only comparable but better than that reported for most instrumented series. ${ }^{32}$ While a statistically significant learning curve was also apparent, interestingly, we noted that the extrusion rates were not related the number of corpectomy levels. ${ }^{32}$ In fact, none of the patients undergoing a 3-level CC experienced graft extrusion. The most common cause of this complication appears to be im- 
proper fashioning of the graft, and this problem is usually completely eliminated as the surgeon's experience grows. Although, even in experienced hands, a fracture of an osteoporotic autograft can still occur, the incidence of this complication in our series was comparable to the incidence in studies reporting outcomes in instrumented CC. Fessler et al. ${ }^{18}$ reported on graft-related and technical complications complications for patients stratified by immobilization technique (halo vest, hard collar, or anterior plate). We analyzed their data using GraphPad and found no statistically significant between-groups differences. Other authors have also demonstrated no statistically significant decrease in graft extrusion rates with additional anterior cervical plating, which may be particularly pertinent for buttress plates and multilevel CC. ${ }^{16,51,55,69}$ Additionally, the high cost and complications related to spinal hardware, therefore, continue to dissuade us from performing instrumentation in our patients. Donor site pain and morbidity is often implicated in a reluctance to use tricortical iliac crest or fibular strut autografts. Serious complications such as local hematomas or infections were very rare in our series, occurring in $0.2 \%$ and $1.9 \%$ of cases, respectively, and no patient required reoperation for harvest-related problems. This compares favorably to what has been described in literature. ${ }^{2,9,13,45,58,59}$ It must be noted, however, that female sex, obesity, and the presence of medical risk factors predispose to morbidity at the harvest site. ${ }^{59}$ Additionally, although our overall infection rate of $3.4 \%$ is relatively low, especially when compared with rates in contemporary reports by authors employing instrumentation, more than half of all surgical infections occurred at the graft site in our series. We acknowledge that cage-assisted reconstruction may provide an attractive alternative to both allo- and autografts, although the biomechanical advantage of a cage in the absence of anterior cervical plating remains uncertain. ${ }^{28}$ Nevertheless, our favorable experience and low rate of morbidity achieved with the uninstrumented $\mathrm{CC}$ over the last 2 decades encourage us to maintain this practice.

\section{Strengths and Limitations of This Study}

This study suffers from limitations inherent to its retrospective nature. We did not have an objective system for documenting nonsevere dysphagia in our patients, nor did we have data on estimated blood loss at surgery. Furthermore, given that this is a single-surgeon series that spans a period of over 15 years, it is uncertain whether surgeon experience may have impacted complication rates in this series. We also do not have data on early settling of fibular grafts, but our experience with long-term subsidence following 3-level $\mathrm{CC}$ has been described in a previous study, ${ }^{22}$ which demonstrated a mean subsidence of $5.7 \mathrm{~mm}$. Although some degree of settling of the graft is associated with fusion, this is usually not significant enough to affect patient outcome or warrant intervention. These limitations notwithstanding, this study describes complication rates in the largest single-surgeon cohort of patients undergoing CC for CSM or OPLL described in literature.

\section{Conclusions}

Complications following CC for CSM and OPLL are infrequent. On multivariate analysis, the execution of a skip corpectomy appears to be significantly associated with the development of complications. OPLL and skip procedures remain the most important risk factors for dural tear. We did not find any risk factors for postoperative C5 palsy, dysphagia or acute graft extrusion after $\mathrm{CC}$.

\section{Acknowledgments}

We would like to thank Mr. Bijesh Yadav for assistance with the statistical analysis for this study.

\section{References}

1. Abe H, Tsuru M, Ito T, Iwasaki Y, Koiwa M: Anterior decompression for ossification of the posterior longitudinal ligament of the cervical spine. J Neurosurg 55:108-116, 1981

2. Ahlmann E, Patzakis M, Roidis N, Shepherd L, Holtom P: Comparison of anterior and posterior iliac crest bone grafts in terms of harvest-site morbidity and functional outcomes. J Bone Joint Surg Am 84-A:716-720, 2002

3. Arnold PM, Rice LR, Anderson KK, McMahon JK, Connelly LM, Norvell DC: Factors affecting hospital length of stay following anterior cervical discectomy and fusion. Evid Based Spine Care J 2:11-18, 2011

4. Ashkenazi E, Smorgick Y, Rand N, Millgram MA, Mirovsky Y, Floman Y: Anterior decompression combined with corpectomies and discectomies in the management of multilevel cervical myelopathy: a hybrid decompression and fixation technique. J Neurosurg Spine 3:205-209, 2005

5. Boakye M, Patil CG, Ho C, Lad SP: Cervical corpectomy: complications and outcomes. Neurosurgery 63 (4 Suppl 2):295-302, 2008

6. Bydon M, Macki M, Kaloostian P, Sciubba DM, Wolinsky JP, Gokaslan ZL, et al: Incidence and prognostic factors of C5 palsy: a clinical study of 1001 cases and review of the literature. Neurosurgery 74:595-605, 2014

7. Campbell PG, Yadla S, Nasser R, Malone J, Maltenfort MG, Ratliff JK: Patient comorbidity score predicting the incidence of perioperative complications: assessing the impact of comorbidities on complications in spine surgery. J Neurosurg Spine 16:37-43, 2012

8. Cardoso MJ, Koski TR, Ganju A, Liu JC: Approach-related complications after decompression for cervical ossification of the posterior longitudinal ligament. Neurosurg Focus 30(3):E12, 2011

9. Chibbaro S, Benvenuti L, Carnesecchi S, Marsella M, Pulerà F, Serino D, et al: Anterior cervical corpectomy for cervical spondylotic myelopathy: experience and surgical results in a series of 70 consecutive patients. J Clin Neurosci 13:233238, 2006

10. Dalbayrak S, Yilmaz M, Naderi S: "Skip" corpectomy in the treatment of multilevel cervical spondylotic myelopathy and ossified posterior longitudinal ligament. J Neurosurg Spine 12:33-38, 2010

11. Edwards CC II, Heller JG, Murakami H: Corpectomy versus laminoplasty for multilevel cervical myelopathy: an independent matched-cohort analysis. Spine (Phila Pa 1976) 27:1168-1175, 2002

12. Eismont FJ, Wiesel SW, Rothman RH: Treatment of dural tears associated with spinal surgery. J Bone Joint Surg Am 63:1132-1136, 1981

13. Eleraky MA, Llanos C, Sonntag VK: Cervical corpectomy: report of 185 cases and review of the literature. J Neurosurg 90 (1 Suppl):35-41, 1999

14. Emery SE, Bohlman HH, Bolesta MJ, Jones PK: Anterior cervical decompression and arthrodesis for the treatment of cervical spondylotic myelopathy. Two to seventeen-year follow-up. J Bone Joint Surg Am 80:941-951, 1998

15. Epstein N: Anterior approaches to cervical spondylosis and 
ossification of the posterior longitudinal ligament: review of operative technique and assessment of 65 multilevel circumferential procedures. Surg Neurol 55:313-324, 2001

16. Epstein NE: Reoperation rates for acute graft extrusion and pseudarthrosis after one-level anterior corpectomy and fusion with and without plate instrumentation: etiology and corrective management. Surg Neurol 56:73-81, 2001

17. Fehlings MG, Smith JS, Kopjar B, Arnold PM, Yoon ST, Vaccaro AR, et al: Perioperative and delayed complications associated with the surgical treatment of cervical spondylotic myelopathy based on 302 patients from the AOSpine North America Cervical Spondylotic Myelopathy Study. J Neurosurg Spine 16:425-432, 2012

18. Fessler RG, Steck JC, Giovanini MA: Anterior cervical corpectomy for cervical spondylotic myelopathy. Neurosurgery 43:257-267, 1998

19. Gandhoke G, Wu JC, Rowland NC, Meyer SA, Gupta C, Mummaneni PV: Anterior corpectomy versus posterior laminoplasty: is the risk of postoperative C-5 palsy different? Neurosurg Focus 31(4):E12, 2011

20. Ghobrial GM, Theofanis T, Darden BV, Arnold P, Fehlings MG, Harrop JS: Unintended durotomy in lumbar degenerative spinal surgery: a 10-year systematic review of the literature. Neurosurg Focus 39(4):E8, 2015

21. Gok B, Sciubba DM, McLoughlin GS, McGirt M, Ayhan S, Wolinsky JP, et al: Surgical treatment of cervical spondylotic myelopathy with anterior compression: a review of 67 cases. J Neurosurg Spine 9:152-157, 2008

22. Gupta A, Rajshekhar V: Functional and radiological outcome in patients undergoing three level corpectomy for multi-level cervical spondylotic myelopathy and ossified posterior longitudinal ligament. Neurol India 64:90-96, 2016

23. Harsh GR IV, Sypert GW, Weinstein PR, Ross DA, Wilson $\mathrm{CB}$ : Cervical spine stenosis secondary to ossification of the posterior longitudinal ligament. J Neurosurg 67:349-357, 1987

24. Hartig D, Batke J, Dea N, Kelly A, Fisher C, Street J: Adverse events in surgically treated cervical spondylopathic myelopathy: a prospective validated observational study. Spine (Phila Pa 1976) 40:292-298, 2015

25. Hasegawa K, Homma T, Chiba Y: Upper extremity palsy following cervical decompression surgery results from a transient spinal cord lesion. Spine (Phila Pa 1976) 32:E197E202, 2007

26. Jimenez JC, Sani S, Braverman B, Deutsch H, Ratliff JK: Palsies of the fifth cervical nerve root after cervical decompression: prevention using continuous intraoperative electromyography monitoring. J Neurosurg Spine 3:92-97, 2005

27. Joseph V, Kumar GSS, Rajshekhar V: Cerebrospinal fluid leak during cervical corpectomy for ossified posterior longitudinal ligament: incidence, management, and outcome. Spine (Phila Pa 1976) 34:491-494, 2009

28. Kandziora F, Pflugmacher R, Schaefer J, Scholz M, Ludwig $\mathrm{K}$, Schleicher P, et al: Biomechanical comparison of expandable cages for vertebral body replacement in the cervical spine. J Neurosurg 99 (1 Suppl):91-97, 2003

29. Kaneyama S, Sumi M, Kanatani T, Kasahara K, Kanemura A, Takabatake M, et al: Prospective study and multivariate analysis of the incidence of C5 palsy after cervical laminoplasty. Spine (Phila Pa 1976) 35:E1553-E1558, 2010

30. Kimura A, Seichi A, Hoshino Y, Yamazaki M, Mochizuki M, Aiba A, et al: Perioperative complications of anterior cervical decompression with fusion in patients with ossification of the posterior longitudinal ligament: a retrospective, multi-institutional study. J Orthop Sci 17:667-672, 2012

31. Kitchel SH, Eismont FJ, Green BA: Closed subarachnoid drainage for management of cerebrospinal fluid leakage after an operation on the spine. J Bone Joint Surg Am 71:984987, 1989
32. Kumar GSS, Rajshekhar V: Acute graft extrusion following central corpectomy in patients with cervical spondylotic myelopathy and ossified posterior longitudinal ligament. J Clin Neurosci 16:373-377, 2009

33. Lau D, Chou D, Mummaneni PV: Two-level corpectomy versus three-level discectomy for cervical spondylotic myelopathy: a comparison of perioperative, radiographic, and clinical outcomes. J Neurosurg Spine 23:280-289, 2015

34. Lin Q, Zhou X, Wang X, Cao P, Tsai N, Yuan W: A comparison of anterior cervical discectomy and corpectomy in patients with multilevel cervical spondylotic myelopathy. Eur Spine J 21:474-481, 2012

35. Liu Y, Hou Y, Yang L, Chen H, Wang X, Wu X, et al: Comparison of 3 reconstructive techniques in the surgical management of multilevel cervical spondylotic myelopathy. Spine (Phila Pa 1976) 37:E1450-E1458, 2012

36. Macdonald RL, Fehlings MG, Tator CH, Lozano A, Fleming JR, Gentili F, et al: Multilevel anterior cervical corpectomy and fibular allograft fusion for cervical myelopathy. J Neurosurg 86:990-997, 1997

37. Marquez-Lara A, Nandyala SV, Hassanzadeh H, Noureldin M, Sankaranarayanan S, Singh K: Sentinel events in cervical spine surgery. Spine (Phila Pa 1976) 39:715-720, 2014

38. Mayr MT, Subach BR, Comey CH, Rodts GE, Haid RW Jr: Cervical spinal stenosis: outcome after anterior corpectomy, allograft reconstruction, and instrumentation. J Neurosurg 96 (1 Suppl): 10-16, 2002

39. McCallum J, Maroon JC, Jannetta PJ: Treatment of postoperative cerebrospinal fluid fistulas by subarachnoid drainage. J Neurosurg 42:434-437, 1975

40. Miller JA, Lubelski D, Alvin MD, Benzel EC, Mroz TE: C5 palsy after posterior cervical decompression and fusion: cost and quality-of-life implications. Spine J 14:2854-2860, 2014

41. Minhas SV, Chow I, Jenkins TJ, Dhingra B, Patel AA: Preoperative predictors of increased hospital costs in elective anterior cervical fusions: a single-institution analysis of 1,082 patients. Spine J 15:841-848, 2015

42. Nakashima H, Imagama S, Yukawa Y, Kanemura T, Kamiya M, Yanase M, et al: Multivariate analysis of C-5 palsy incidence after cervical posterior fusion with instrumentation. J Neurosurg Spine 17:103-110, 2012

43. Nandyala SV, Elboghdady IM, Marquez-Lara A, Noureldin MN, Sankaranarayanan S, Singh K: Cost analysis of incidental durotomy in spine surgery. Spine (Phila Pa 1976) 39:E1042-E1051, 2014

44. Nassr A, Eck JC, Ponnappan RK, Zanoun RR, Donaldson WF III, Kang JD: The incidence of C5 palsy after multilevel cervical decompression procedures: a review of 750 consecutive cases. Spine (Phila Pa 1976) 37:174-178, 2012

45. Nassr A, Khan MH, Ali MH, Espiritu MT, Hanks SE, Lee JY, et al: Donor-site complications of autogenous nonvascularized fibula strut graft harvest for anterior cervical corpectomy and fusion surgery: experience with 163 consecutive cases. Spine J 9:893-898, 2009

46. O’Neill KR, Neuman BJ, Peters C, Riew KD: Risk factors for dural tears in the cervical spine. Spine (Phila Pa 1976) 39:E1015-E1020, 2014

47. Odate S, Shikata J, Yamamura S, Soeda T: Extremely wide and asymmetric anterior decompression causes postoperative C5 palsy: an analysis of 32 patients with postoperative C5 palsy after anterior cervical decompression and fusion. Spine (Phila Pa 1976) 38:2184-2189, 2013

48. Puffer RC, Clifton WE, Mallory GW, Clarke MJ: Delayed cervical palsy following cervical spine fusion leads to an increase in hospital-related costs. J Neurosurg Spine 22:11-14, 2015

49. Rajshekhar V, Arunkumar MJ, Kumar SS: Changes in cervical spine curvature after uninstrumented one- and two-level corpectomy in patients with spondylotic myelopathy. Neurosurgery 52:799-805, 2003 
50. Rajshekhar V, Kumar GSS: Functional outcome after central corpectomy in poor-grade patients with cervical spondylotic myelopathy or ossified posterior longitudinal ligament. Neurosurgery 56:1279-1285, 2005

51. Riew KD, Sethi NS, Devney J, Goette K, Choi K: Complications of buttress plate stabilization of cervical corpectomy. Spine (Phila Pa 1976) 24:2404-2410, 1999

52. Sagi HC, Beutler W, Carroll E, Connolly PJ: Airway complications associated with surgery on the anterior cervical spine. Spine (Phila Pa 1976) 27:949-953, 2002

53. Sakaura H, Hosono N, Mukai Y, Ishii T, Yoshikawa H: C5 palsy after decompression surgery for cervical myelopathy: review of the literature. Spine (Phila Pa 1976) 28:24472451, 2003

54. Sasai K, Saito T, Akagi S, Kato I, Ohnari H, Iida H: Preventing C5 palsy after laminoplasty. Spine (Phila Pa 1976) 28:1972-1977, 2003

55. Sasso RC, Ruggiero RA Jr, Reilly TM, Hall PV: Early reconstruction failures after multilevel cervical corpectomy. Spine (Phila Pa 1976) 28:140-142, 2003

56. Satomi K, Nishu Y, Kohno T, Hirabayashi K: Long-term follow-up studies of open-door expansive laminoplasty for cervical stenotic myelopathy. Spine (Phila Pa 1976) 19:507510,1994

57. Saunders RL: On the pathogenesis of the radiculopathy complicating multilevel corpectomy. Neurosurgery 37:408-413, 1995

58. Saunders RL, Bernini PM, Shirreffs TG Jr, Reeves AG: Central corpectomy for cervical spondylotic myelopathy: a consecutive series with long-term follow-up evaluation. J Neurosurg 74:163-170, 1991

59. Schnee CL, Freese A, Weil RJ, Marcotte PJ: Analysis of harvest morbidity and radiographic outcome using autograft for anterior cervical fusion. Spine (Phila Pa 1976) 22:22222227, 1997

60. Shinomiya K, Kurosa Y, Fuchioka M, Furuya K: Clinical study of dissociated motor weakness following anterior cervical decompression surgery. Spine (Phila Pa 1976) 14:1211-1214, 1989

61. Sin AH, Caldito G, Smith D, Rashidi M, Willis B, Nanda A: Predictive factors for dural tear and cerebrospinal fluid leakage in patients undergoing lumbar surgery. J Neurosurg Spine 5:224-227, 2006

62. Singh K, Marquez-Lara A, Nandyala SV, Patel AA, Fineberg SJ: Incidence and risk factors for dysphagia after anterior cervical fusion. Spine (Phila Pa 1976) 38:1820-1825, 2013

63. Smith MD, Bolesta MJ, Leventhal M, Bohlman HH: Postoperative cerebrospinal-fluid fistula associated with erosion of the dura. Findings after anterior resection of ossification of the posterior longitudinal ligament in the cervical spine. $\mathbf{J}$ Bone Joint Surg Am 74:270-277, 1992

64. Smith ZA, Buchanan CC, Raphael D, Khoo LT: Ossification of the posterior longitudinal ligament: pathogenesis, management, and current surgical approaches. A review. Neurosurg Focus 30(3):E10, 2011

65. Song KJ, Lee KB, Song JH: Efficacy of multilevel anterior cervical discectomy and fusion versus corpectomy and fusion for multilevel cervical spondylotic myelopathy: a minimum 5-year follow-up study. Eur Spine J 21:1551-1557, 2012

66. Takahashi Y, Sato T, Hyodo H, Kawamata T, Takahashi E, Miyatake N, et al: Incidental durotomy during lumbar spine surgery: risk factors and anatomic locations: clinical article. J Neurosurg Spine 18:165-169, 2013

67. Tetreault L, Ibrahim A, Côté P, Singh A, Fehlings MG: A systematic review of clinical and surgical predictors of complications following surgery for degenerative cervical myelopathy. J Neurosurg Spine 24:77-99, 2015

68. Tsuzuki N, Abe R, Saiki K, Zhongshi L: Extradural tethering effect as one mechanism of radiculopathy complicating posterior decompression of the cervical spinal cord. Spine (Phila Pa 1976) 21:203-211, 1996

69. Vaccaro AR, Falatyn SP, Scuderi GJ, Eismont FJ, McGuire RA, Singh K, et al: Early failure of long segment anterior cervical plate fixation. J Spinal Disord 11:410-415, 1998

70. Wada E, Suzuki S, Kanazawa A, Matsuoka T, Miyamoto S, Yonenobu K: Subtotal corpectomy versus laminoplasty for multilevel cervical spondylotic myelopathy: a longterm follow-up study over 10 years. Spine (Phila Pa 1976) 26:1443-1448, 2001

71. Yonenobu K, Hosono N, Iwasaki M, Asano M, Ono K: Neurologic complications of surgery for cervical compression myelopathy. Spine (Phila Pa 1976) 16:1277-1282, 1991

\section{Disclosures}

The authors report no conflict of interest concerning the materials or methods used in this study or the findings specified in this paper.

\section{Author Contributions}

Conception and design: Rajshekhar. Acquisition of data: all authors. Analysis and interpretation of data: Rajshekhar, Sarkar. Drafting the article: all authors. Critically revising the article: Rajshekhar, Sarkar. Reviewed submitted version of manuscript: all authors. Approved the final version of the manuscript on behalf of all authors: Rajshekhar. Statistical analysis: Sarkar. Administrative/technical/material support: Rajshekhar, Nair. Study supervision: Rajshekhar.

\section{Correspondence}

Vedantam Rajshekhar, Department of Neurological Sciences, Christian Medical College, Vellore 632004, India. email: rajshekhar@cmcvellore.ac.in. 